\title{
Role of the faecal stream in the maintenance of Crohn's colitis
}

\author{
P H HARPER, E C G LEE, M G W KETTLEWELL, \\ $M$ K BENNETT, AND D P JEWELL \\ From the John Radcliffe Hospital, Oxford
}

SUMmARY The role of the faecal stream in the maintenance of the inflammation in Crohn's disease has been studied. Small bowel effluent and a sterile ultrafiltrate of it were reintroduced into the defunctioned colon of patients with Crohn's colitis treated by split ileostomy. The systemic effect of these challenges on the patients was assessed clinically and by laboratory tests, and the effect on the local disease was assessed by endoscopy, histology, and quantitative analysis of lamina propria plasma cell populations. There was little response to the ultrafiltrate challenge. In contrast the clinical responses to challenge with ileostomy effluent were marked in some patients. One patient relapsed and eight others had clinically detectable responses. On the other hand changes in laboratory, endoscopic, histological, and morphometric tests in response to the faecal challenge were less pronounced. The only significant changes in the laboratory results were a relative lymphopenia $(p<0.05)$ and a raised ESR $(p<0.02)$ after seven days challenge with the effluent. The plasma cell density also increased but not significantly. In conclusion, these results suggest that factors greater than 0.22 microns in the faecal stream are responsible for the maintenance and exacerbation of inflammation in Crohn's disease.

The cause of Crohn's disease is still unknown despite years of intensive research and study. Exclusion of the faecal stream from the diseased bowel has been successfully used in the treatment of many patients. This can be achieved medically by total parenteral nutrition ${ }^{1-4}$ or elemental diets ${ }^{5} 6$ and surgically by split ileostomy ${ }^{7}$ or loop ileostomy. ${ }^{8}$ This improvement suggests that factor(s) in the faecal stream are important in the maintenance of the inflammation and possibly in the aetiology of the disease.

This hypothesis has been investigated by the reintroduction of faecal material into the defunctioned colon of patients with Crohn's disease treated by split ileostomy. ${ }^{9}$ The effect of this challenge on the colon and the patients' response to it were assessed both systemically by clinical examination and laboratory tests and locally by colonoscopy and multiple biopsy.

An initial attempt to identify the nature of possible 'factor(s)' within the faecal stream was

Address for correspondence: Mr P H Harper. FRCS. Senior Surgical Registrar, Royal Victoria Infirmary, Newcastle upon Tyne.

Received for publication 1 June 1984 made. Clostridium difficile toxin, the cause of pseudomembranous colitis, is only occasionally present in Crohn's disease ${ }^{10}$ but it is possible that a similar toxin or antigen in the faecal stream may be aetiologically important in Crohn's disease. To examine this possibility a sterile bacteria and virus free 'ultrafiltrate' fraction of the faecal stream was prepared.

\section{Methods}

\section{PATIENTS}

Twenty two patients with Crohn's disease of the colon diagnosed by the criteria of LockhartMummery and Morson ${ }^{11}{ }^{12}$ were studied. They had all failed to make a good response to medical therapy and had received a split ileostomy. The operation had been performed at least six months before they were entered into the study. The disease was quiescent in all patients but two were receiving small doses of corticosteroids and two salazopyrin.

\section{CHALLENGES}

The challenges were infused using a $60 \mathrm{ml}$ syringe and a Foley catheter. Seven patients with Crohn's 
colitis had small bowel effluent (mean volume 50 $\mathrm{ml} /$ day) introduced per anum into the defunctioned colon daily for seven days in hospital. Most patients were able to retain this challenge for the 24 hours before the next challenge. A further eight patients infused small bowel effluent into their mucous fistulae daily for 28 days (mean volume $115 \mathrm{ml} /$ day) at home. Each patient started regular daily defaecation within three days of the start of the challenge. An ultrafiltrate of the small bowel contents, prepared as below, was introduced per rectum daily for seven days in seven other patients.

\section{PREPARATION OF THE ULTRAFILTRATE}

The ultrafiltrate fraction was prepared daily from fresh small bowel effluent by centrifuging two hundred millilitres at $10000 \mathrm{rpm}$ for one hour. The supernatant was removed and if this was particulate it was respun for the same time at the same speed. The supernatant was then diluted with an equal volume of distilled water to facilitate its filtration through graded Millipore filters from 5.0 to 0.22 microns pore size. The ultrafiltrate was finally collected in a sterile container and $1 \mathrm{ml}$ aliquots sent for bacteriological and virological sterility checks. Two samples were not sterile: one grew a scanty growth of faecal streptococci and another an ECHO virus, Type 17 . The mean daily volume instilled was $70 \mathrm{ml}$.

\section{ASSESSMENT}

All patients were assessed before and after their challenges - that is, at 0 and 8 , or 28 days. An additional assessment was made on day 8 of the 28 day faecal challenge patients to add to the number of results of the seven day faecal challenge group. The assessment of the response to the challenges was performed in three ways.

\section{Clinical}

A full history and examination was taken from each patient with Crohn's disease at the start of each study. This was repeated at subsequent assessments when particular attention was given to the occurrence of new symptoms and signs or changes in existing ones.

\section{Laboratory tests}

The haematological and biochemical estimations were made in the routine laboratories of the John Radcliffe Hospital. Estimations of C-reactive protein (CRP), orosomucoid and immunoglobulin serum concentrations were performed on a rate nephelometer (Beckman Immunochemistry Analyser) using ICS Reagent Test Kits (Beckman Instruments Inc).

\section{Endoscopy and biopsy}

A full colonoscopy was performed on each patient with Crohn's disease before and after their challenges. A sigmoidoscopy was performed on day 8 in the patients receiving the 28 day challenge with ileostomy effluent. The extent and the severity of the colonic disease was recorded at each colonoscopy.

Multiple biopsies were taken, including rectal biopsies, at each colonoscopy. At the second colonoscopy further biopsies were taken as close to the original site as possible, which in practice meant that all biopsies had to be taken at anatomical and pathological 'landmarks'. A rectal biopsy was obtained at the sigmoidoscopic examination.

The biopsies were orientated on filter paper with their mucosa uppermost. They were then fixed in formol sublimate ${ }^{13}$ and dehydrated in a graded series of ethanol solutions, cleared in chloroform and embedded in paraffin wax. Sections of 2 microns thickness were cut vertical to the mucosal surface. They were stained with haematoxylin and eosin for histological examination. In addition an indirect immunoperoxidase technique ${ }^{14}$ was used to identify the IgA, IgG, and IgM plasma cell subpopulations for morphometric analysis. The antisera used (rabbit anti-human IgA, rabbit anti-human IgG and rabbit anti-human IgM and peroxidase-conjugated swine anti-rabbit IgG) were obtained commercially (DAKO-immunoglobulin Ltd, Denmark). The method and antisera have been widely used. ${ }^{15}$ The haematoxylin and eosin sections were assessed 'blind' by a single observer (MKB) for the severest degree of chronic inflammatory infiltrate seen in each biopsy and this was recorded on a scale of normal, mild, moderate, or severe. Biopsies taken from the same sites before and after the challenges were then compared to identify any change in the severity of inflammation.

\section{MORPHOMETRY}

Plasma cell densities per millimetre of muscularis mucosa and per $\mathrm{mm}^{2}$ of lamina propria were measured using a semiautomated counting and data storage unit (MOP-AM-03, Reichart-Jung, UK). Sufficient fields were counted so that early fluctuations of the plasma cell density on average summation graphs ${ }^{16}$ levelled out. All fields included the whole lamina propria from muscularis mucosa to epithelium because the distribution of plasma cells in the lamina propria is not random. ${ }^{17}$

The densities of individual plasma cell types and total plasma cell densities (IgA + IgG+IgM) were measured on the rectal biopsies as these were available on all patients. Furthermore, the rectum is a uniform site for comparison as there are differ- 
ences in plasma cell populations between areas of the colon. ${ }^{18}$ The ratio of lamina propria area to muscularis mucosal length was calculated on each rectal biopsy as a measure of lamina propria volume. $^{19}$

\section{STATISTICS}

Results which were normally distributed were analysed using a paired $t$ test, and non-parametric results by Wilcoxon's signed rank test for paired data.

\section{ETHICS}

The study had been approved by the Ethics Committee of the John Radcliffe Hospital. Patients gave written consent after a full explanation had been given and after reading a simple description of the study and its aims.

\section{Results}

\section{CLINICAL}

Nine of 15 patients with Crohn's disease suffered a clinical response to challenge with ileostomy effluent. These effects all started within the first week of the challenge. One patient developed a relapse of disease. She suffered severe colicky abdominal pain associated with nausea and vomiting from the start of her challenge and her abdomen became tender in the left hypochondrium. The challenge was stopped and she was intensively treated with steroids but her symptoms did not completely resolve until after a proctocolectomy. She is now fit and well. In the other eight patients, three experienced minor colicky abdominal pain, accompanied by persistent diarrhoea in one patient, early in their challenge. Oral aphthoid ulceration developed and persisted in another during the course of the 28 day challenge and only cleared after its completion. Mucus discharge per rectum and perianal irritation developed in two further patients and in one progressed to a perianal abscess after completion of a 28 day study. One patient became depressed as she found the infusion of effluent into her mucous fistula unpleasant. Her study was stopped after eight days.

The ultrafiltrate challenge caused no clinical effects in any of the seven patients who received it.

\section{LABORATORY TESTS}

The results of laboratory tests for the effluent and ultrafiltrate challenges are shown in Tables 1 and 2 . There is little change in patients challenged with the ultrafiltrate but after challenge with ileostomy effluent there was a slight rise in the neutrophil count and significant relative lymphopenia at eight days $(\mathrm{p}<0.05)$. These changes were less marked after the 28 day challenge. The ESR rose significantly $(p<0.02)$ but the other indices of inflammation and immunoglobulin concentrations showed no significant change.

\section{ENDOSCOPY}

Colonoscopic examination of the defunctioned colon is different from colonoscopy of the functioning bowel. The colon is contracted and contains a viscid mucus which needs to be cleared before the examination with an enema. Air insufflation dilates the colon partially but angulation at the flexures can be acute and makes intubation difficult. In contrast the shortened colon is often easier to intubate without the redundant loops of a functioning bowel.

In defunctioned Crohn's disease macroscopic features of the disease are often visible. No change in the degree of the inflammation was observed in response to the challenges with either ileostomy effluent or the ultrafiltrate.

Table 1 Mean haematological changes $( \pm S D)$ in response to the ileostomy effluent and ultrafiltrate challenges

\begin{tabular}{|c|c|c|c|c|c|c|}
\hline & \multicolumn{2}{|c|}{ Faecal-7 (day) } & \multicolumn{2}{|c|}{ Faecal-28 (day) } & \multicolumn{2}{|c|}{ Ultrafiltrate (day) } \\
\hline & 0 & 8 & 0 & 28 & 0 & 8 \\
\hline Haemoglobin (g/dl) & $14 \cdot 39 \pm 1 \cdot 12$ & $14 \cdot 21 \pm 1 \cdot 40$ & $14 \cdot 96 \pm 1 \cdot 08$ & $14 \cdot 89 \pm 1 \cdot 24$ & $14 \cdot 33 \pm 1 \cdot 67$ & $14 \cdot 34 \pm 1 \cdot 59$ \\
\hline White blood count $\left(\times 10^{9}\right)$ & $8 \cdot 87 \pm 1 \cdot 86$ & $10 \cdot 09 \pm 5 \cdot 23$ & $8 \cdot 51 \pm 2 \cdot 29$ & $9.70 \pm 5.06$ & $7 \cdot 70 \pm 0.95$ & $7 \cdot 34 \pm 0.84$ \\
\hline Neutrophil count & $5 \cdot 81 \pm 1 \cdot 58$ & $7 \cdot 46 \pm 5 \cdot 13$ & $5 \cdot 50 \pm 2 \cdot 04$ & $6 \cdot 50 \pm 4 \cdot 18$ & $4 \cdot 99 \pm 1 \cdot 30$ & $4 \cdot 56 \pm 1 \cdot 20$ \\
\hline$\%$ & $64 \cdot 9 \pm 9 \cdot 2$ & $70 \cdot 6 \pm 12 \cdot 4$ & $63 \cdot 3 \pm 8 \cdot 2$ & $66 \cdot 9 \pm 15 \cdot 9$ & $64 \cdot 0 \pm 9 \cdot 5$ & $61 \cdot 7 \pm 12 \cdot 6$ \\
\hline$\%$ & $25 \cdot 4 \pm 7 \cdot 4$ & $20 \cdot 2 \pm 9 \cdot 6^{*}$ & $27 \cdot 0 \pm 7 \cdot 2$ & $24 \cdot 4 \pm 12 \cdot 0$ & $28 \cdot 1 \pm 7 \cdot 6$ & $30 \cdot 6 \pm 10 \cdot 8$ \\
\hline Monocyte count & $0 \cdot 57 \pm 0.29$ & $0.60 \pm 0.29$ & $0.54 \pm 0.18$ & $0.64 \pm 0.49$ & $0.43 \pm 0.16$ & $0.43 \pm 0.22$ \\
\hline$\%$ & $6 \cdot 6 \pm 3 \cdot 0$ & $7 \cdot 1 \pm 2 \cdot 7$ & $6 \cdot 9 \pm 2 \cdot 8$ & $7 \cdot 0 \pm 1 \cdot 9$ & $5 \cdot 7 \pm 2 \cdot 6$ & $5 \cdot 7 \pm 3 \cdot 2$ \\
\hline Eosinophil count & $0.24 \pm 0.27$ & $0 \cdot 22 \pm 0 \cdot 17$ & $0 \cdot 30 \pm 0 \cdot 34$ & $0.20 \pm 0.33$ & $0 \cdot 19 \pm 0 \cdot 12$ & $0 \cdot 14 \pm 0 \cdot 11$ \\
\hline$\%$ & $2 \cdot 5 \pm 2 \cdot 3$ & $3 \cdot 1 \pm 3 \cdot 3$ & $2 \cdot 9 \pm 2 \cdot 6$ & $1 \cdot 7 \pm 1 \cdot 9$ & $2 \cdot 1 \pm 1 \cdot 5$ & $1 \cdot 9 \pm 1 \cdot 8$ \\
\hline
\end{tabular}

${ }^{*} \mathrm{p}<0 \cdot 05$. 
Table 2 Changes in the means $( \pm S D)$ of other laboratory measurements in response to the faecal and ultrafiltrate challenges

\begin{tabular}{|c|c|c|c|c|c|c|}
\hline & \multicolumn{2}{|c|}{ Faecal-7 (day) } & \multicolumn{2}{|c|}{ Faecal-28 (day) } & \multicolumn{2}{|c|}{ Ultrafiltrate (day) } \\
\hline & 0 & 8 & 0 & 28 & 0 & 8 \\
\hline Albumin $(g / l)$ & $43 \cdot 1 \pm 3 \cdot 4$ & $42 \cdot 4 \pm 2 \cdot 9$ & $43 \cdot 9 \pm 4 \cdot 1$ & $43 \cdot 1 \pm 3 \cdot 7$ & $42 \cdot 7 \pm 5 \cdot 4$ & $44 \cdot 3 \pm 3 \cdot 6$ \\
\hline $\operatorname{ESR}(\mathrm{mm} / \mathrm{h})$ & $8 \cdot 3 \pm 9 \cdot 1$ & $17 \cdot 5 \pm 17 \cdot 8^{*}$ & $4.9 \pm 3.6$ & $11 \cdot 1 \pm 17 \cdot 3$ & $11 \cdot 9 \pm 12 \cdot 0$ & $10 \cdot 1 \pm 8 \cdot 3$ \\
\hline CRP (mg/dl) & $1 \cdot 26 \pm 1 \cdot 33$ & $1 \cdot 11 \pm 0.66$ & $1.83 \pm 1.92$ & $1.32 \pm 1.07$ & $0.71 \pm 0.19$ & $0.77 \pm 0.26$ \\
\hline Orosomucoids (mg/dl) & $77 \cdot 8 \pm 23 \cdot 3$ & $81 \cdot 9 \pm 26 \cdot 2$ & $77 \cdot 2 \pm 24 \cdot 1$ & $72 \cdot 7 \pm 18 \cdot 0$ & $67 \cdot 4 \pm 16 \cdot 2$ & $66 \cdot 9 \pm 11 \cdot 9$ \\
\hline $\operatorname{Ig} A(g / l)$ & $2.55 \pm 1.09$ & $2 \cdot 64 \pm 1 \cdot 12$ & $3 \cdot 03 \pm 1 \cdot 35$ & $2 \cdot 87 \pm 1 \cdot 17$ & $2.80 \pm 0.98$ & $2 \cdot 93 \pm 1 \cdot 18$ \\
\hline $\mathrm{IgG}(\mathrm{g} / \mathrm{l})$ & $12 \cdot 26 \pm 4 \cdot 18$ & $12 \cdot 19 \pm 4 \cdot 45$ & $11.97 \pm 2.75$ & $11 \cdot 48 \pm 2.85$ & $11 \cdot 20 \pm 3 \cdot 32$ & $11 \cdot 50 \pm 3 \cdot 15$ \\
\hline $\operatorname{IgM}(g / 1)$ & $1.69 \pm 0.65$ & $1 \cdot 90 \pm 1 \cdot 15$ & $1.68 \pm 0.79$ & $1.65 \pm 0.65$ & $1 \cdot 77 \pm 0 \cdot 51$ & $1.83 \pm 0.36$ \\
\hline
\end{tabular}

${ }^{*} \mathrm{p}<0.02$.

\section{HISTOLOGY}

No changes in the degree of chronic inflammatory infiltration in the lamina propria were seen over the course of either the effluent or ultrafiltrate challenges. IgA and IgM plasma cells were seen mostly in the more superficial levels of the lamina propria whereas the IgG cells mostly lay nearer the muscularis mucosa.

\section{MORPHOMETRY}

Morphometric analysis was impossible on the biopsies of four patients with Crohn's disease because the biopsies were not satisfactory. The lamina propria volumes did not alter significantly in response to either the ileostomy effluent or ultrafiltrate challenges (Table 3).

The total plasma cell densities per $\mathrm{mm}^{2}$ of lamina propria and per $\mathrm{mm}$ of muscularis mucosa gradually increased over the course of the faecal challenge but very little during the ultrafiltrate challenge (Table 4).

The mean proportions of the subpopulations of plasma cells in the patients altered very little except after one week of challenge with ileostomy effluent (Table 5). There was a significant rise in the IgG cells at the expense of IgM. At 28 days, however, the initial proportions were virtually restored. The proportions were unchanged after the ultrafiltrate challenge.

Table 3 Changes in the mean ratios of lamina propria area and muscularis mucosa length $( \pm S D)$ as a measure of lamina propria volume

\begin{tabular}{llr}
\hline & \multicolumn{2}{l}{ Mean volume } \\
\cline { 2 - 3 } Challenge & \multicolumn{1}{c}{$8 / 28$} \\
\hline Faecal-7 & $15 \cdot 3 \pm 8 \cdot 7$ & $16 \cdot 9 \pm 9 \cdot 5$ \\
Faecal-28 & $14 \cdot 2 \pm 2 \cdot 3$ & $14 \cdot 1 \pm 3 \cdot 6$ \\
Ultrafiltrate & $9 \cdot 9 \pm 0 \cdot 7$ & $9 \cdot 7 \pm 2 \cdot 1$ \\
\hline
\end{tabular}

\section{Discussion}

The defunctioned colon in patients with Crohn's disease of the colon is a unique model in which to test the hypothesis that the faecal stream is important for the pathogenesis of the inflammation. Its advantages are in allowing a dynamic assessment of the patients response to a controlled reintroduction of faecal material into the colon when the disease is quiescent. Clinical, laboratory, endoscopic, histological, and morphometric parameters recorded before and after the challenge provide good evidence of disease activity.

The clinical responses to the challenge with ileostomy effluent were dramatic especially as the effects all started within the first week and were mostly persistent throughout the period of challenge. While the abdominal colic may have been caused by the passage of stool through a contracted colon and the diarrhoea to the short length of remaining bowel other features such as oral aphthoid ulceration and perianal disease are indicators of a relapse of disease caused by the challenge. The 'depressive' episode was a reaction to the infusion of the ileostomy effluent and not the

Table 4 Changes in the mean densities of plasma cells $( \pm S D)$ after challenge with ileostomy effluent or an ultrafiltrate

\begin{tabular}{lll}
\hline & \multicolumn{2}{l}{ Density } \\
\cline { 2 - 3 } & 0 & $8 / 28$ \\
\hline Total cells/mm $/ m^{2}$ lamina propria: & \\
Faecal-7 & $2042 \pm 1453$ & $2204 \pm 1045$ \\
Faecal-28 & $1472 \pm 687$ & $2129 \pm 858$ \\
Uiltrafiltrate & $1969 \pm 1237$ & $2108 \pm 1053$ \\
Total cells/mm muscularis mucosa: & \\
Faecal-7 & $582 \pm 771$ & $614 \pm 516$ \\
Faecal-28 & $319 \pm 147$ & $433 \pm 31$ \\
Ultrafiltrate & $304 \pm 183$ & $317 \pm 184$ \\
\hline
\end{tabular}


Table 5 Change in the mean proportions $( \pm S D)$ of plasma cells $/ \mathrm{mm}^{2}$ lamina propria in response to challenges in patients with Crohn's disease

\begin{tabular}{lcc}
\hline \multicolumn{3}{c}{ Proportions } \\
\cline { 2 - 3 } & 0 & $8 / 28$ \\
\hline Faecal-7: & & \\
IgA & $81 \cdot 3 \pm 13 \cdot 3$ & $80 \cdot 5 \pm 11 \cdot 0$ \\
IgG & $7 \cdot 8 \pm 9 \cdot 2$ & $11 \cdot 3 \pm 9 \cdot 5^{*}$ \\
IgM & $11 \cdot 1 \pm 9 \cdot 4$ & $8 \cdot 3 \pm 3 \cdot 1$ \\
Faecal-28: & & \\
IgA & $86 \cdot 8 \pm 4 \cdot 0$ & $84 \cdot 4 \pm 4 \cdot 9$ \\
IgG & $4 \cdot 4 \pm 2 \cdot 1$ & $5 \cdot 2 \pm 2 \cdot 6$ \\
IgM & $9 \cdot 0 \pm 4 \cdot 0$ & $10 \cdot 4 \pm 3 \cdot 2$ \\
Ultrafiltrate: & & \\
IgA & $87 \cdot 2 \pm 8 \cdot 1$ & $88 \cdot 7 \pm 4 \cdot 9$ \\
IgG & $6 \cdot 3 \pm 6 \cdot 8$ & $4 \cdot 8 \pm 3 \cdot 3$ \\
IgM & $6 \cdot 7 \pm 1 \cdot 6$ & $6 \cdot 7 \pm 2 \cdot 2$ \\
\hline p & & \\
\hline
\end{tabular}

challenge itself.

In contrast the overall results of laboratory and morphological tests only showed a small response to the faecal challenge. Even so, marked changes in laboratory indices were seen in a few patients although these were masked in the overall results.

The rise in the neutrophil count after the challenge with effluent is consistent with the findings of Thayer $e t a l^{20}$ and Auer $e t a l^{21}$ who have shown a leucocytosis in active Crohn's disease. In active disease, Auer $e t a^{21}$ also reported an absolute and relative lymphopenia which was apparent in this study. It is possible that circulating lymphocytes are attracted to the colonic mucosa in response to the challenge. Andre $e t a^{22}$ have shown that ESR, CRP, and orosmucoid levels are the best indicators of disease activity but in this study only the ESR increased in response to the challenge with ileostomy effluent.

There were no changes in the endoscopic or histological appearances of inflammation in response to the long or short challenges, which is surprising in view of the clinical and serological changes. Endoscopic changes are, however, very subjective and therefore it would be easy to miss them particularly if they were slight or patchy. Biopsies are small and the disease focal which means that the active microscopic inflammation could easily be missed.

Challenge with ileostomy effluent, however, caused small increases of rectal lamina propria plasma cell densities and at the same time the proportion of IgG cells slightly increased mostly at the expense of IgM cells (Table 5). Similar differences in mucosal plasma cell densities and popula- tions are reported between active and quiescent disease. ${ }^{19} 2324$

In contrast there was virtually no response to the ultrafiltrate challenge in patients with Crohn's disease of the colon. During the preparation of the challenge some of the filtrate was unavoidably lost and it is possible that the volume instilled into the colon was insufficient to elicit a response. The ultrafiltrate, however, reached the whole colon as shown by the leakage of it from the mucous fistula after instillation per rectum. The failure of the ultrafiltrate to initiate any change suggests that factors greater than $\mathbf{0 . 2 2}$ microns are responsible for the maintenance of the inflammation in Crohn's disease.

PHH was in receipt of a Wellcome Surgical Research Fellowship. Professor P J Morris and Dr Helen Chapel kindly provided laboratory facilities.

\section{References}

1 Greenberg GR, Haber GB, Jeejeebhoy KN. Total parenteral nutrition (TPN) and bowel rest in the management of Crohn's disease. Gut 1976; 17 : 828.

2 Rosenberg IH. Nutritional support in inflammatory bowel disease. Gastroenterology 1979; 77: 393-6.

3 Elson CO, Layden TJ, Nemchausky BA, Rosenberg JL, Rosenberg IH. An evaluation of total parenteral nutrition in the management of inflammatory bowel disease. Dig Dis Sci 1980; 25: 42-8.

4 Holm I. Benefits of total parenteral nutrition (TPN) in the treatment of Crohn's disease and ulcerative colitis. Acta Chir Scand 1981; 147: 271-6.

5 O'Morain C, Segal AW, Levi AJ. Elemental diets in treatment of acute Crohn's disease. Br Med J 1980; 281: 1173-5.

6 Logan RFA, Gillon J, Ferrington C, Ferguson A. Reduction of gastrointestinal protein loss by elemental diet in Crohn's disease of the small bowel. Gut 1981; 22: 383-7.

7 Harper PH, Truelove SC, Lee ECG, Kettlewell MGW, Jewell DP. Split ileostomy and ileocolostomy for Crohn's disease of the colon and ulcerative colitis: a 20 year survey. Gut 1983; 24: 106-13.

8 Zelas P, Jagelman DG. Loop ileostomy in the management of Crohn's colitis in the debilitated patient. Ann Surg 1980; 191: 164-8.

9 Lee E. Split ileostomy in the treatment of Crohn's disease of the colon. Ann R Coll Surg Engl 1975; 56: 94-102.

10 Trnka YM, LaMont JT. Association of clostridium difficile toxin with symptomatic relapse of chronic inflammatory bowel disease. Gastroenterology 1981; 80: 693-6.

11 Lockhart-Mummery HE, Morson BC. Crohn's disease (Regional enteritis) of the large intestine and its 
distinction from ulcerative colitis. Gut 1960; 1: 87-105.

12 Lockhart-Mummery HE, Morson BC. Crohn's disease of the large intestine. Gut 1964; 5: 493-509.

13 Piris $J$, Thomas ND. A quantitative study of the influence of fixation on immunoperoxidase staining of rectal mucosal plasma cells. J Clin Pathol 1980; 33: $361-4$.

14 Burns J. Immunohistological methods and their application in the routine laboratory. In: Anthony PP, Woolf $\mathrm{N}$, eds. Recent advances in histopathology, 10. Edinburgh: Churchill Livingstone, 1978: 337-50.

15 Taylor CR, Burns J. The demonstration of plasma cells and other immunoglobulin-containing cells in formalin fixed, paraffin-embedded tissues using peroxidaselabelled antibody. J Clin Pathol 1974; 27: 14-20.

16 Dunnill MS. Quantitative methods in histology. In: Dyke SC, ed. Recent advances of clinical pathology, series V. London: Churchill Livingstone, 1968: 401-16.

17 Leonard RCF, Maclennan ICM. Distribution of plasma cells in normal rectal mucosa. J Clin Pathol 1982; 35: 820-3.

18 Crabbe PA, Heremans JF. The distribution of immunoglobulin-containing cells along the human gastrointestinal tract. Gastroenterology 1966; 51: 30516.
19 Rosekrans PCM, Meijer CJLM, Van der Wal AM, Cornelisse CJ, Linderman J. Immunoglobulin containing cells in inflammatory bowel disease of the colon: a morphometric and immunohistochemical study. Gut 1980; 21 : 941-7.

20 Thayer WR, Charland C, Field CE. The subpopulations of circulating white blood cells in inflammatory bowel disease. Gastroenterology 1976; 71: 379-84.

21 Auer IO, Wechsler W, Ziemer E, Malchow $\mathrm{H}$, Sommer H. Immune status in Crohn's disease. 1. Leucocyte and lymphocyte subpopulations in peripheral blood. Scand J Gastroenterol 1978; 13: 561-571.

22 Andre C, Descos L, Landais P, Fermanian J. Assessment of appropriate laboratory measurements to supplement the Crohn's disease activity index. Gut 1981; 22: 571-4.

23 Baklien K, Brandtzaeg P. Comparative mapping of the local distribution of immunoglobulin-containing cells in ulcerative colitis and Crohn's disease of the colon. Clin Exp Immunol 1975; 22: 197-209.

24 Meijer CJLM, Bosman FT, Lindeman J. Evidence for predominant involvement of the B-cell system in the inflammatory process in Crohn's disease. Scand $J$ Gastroenterol 1979; 14: 21-22. 